\title{
A COMPARATIVE STUDY OF SMALL LONG-LIFE GAS COOLED FAST REACTOR
}

\author{
Rio Anshari \\ Fakultas Matematika dan Ilmu Pengetahuan Alam, Universitas Negeri Padang \\ email: rio.anshari@gmail.com
}

\begin{abstract}
In this paper, a comparative study has been carried out of gas reactor type Small Long-Life Gas Cooled Fast Reactor in some associated designs as its one of the candidates generation IV reactors that are expected to start operating in 2030. The comparative study has been done with study focuses on the role of the reactor in economics, safety systems, reactor waste management and proliferation resistance. The results of the study showed it has highly prospects for the operation because of their role in supporting economic growth and transport systems, passive safety systems based on natural circulation, the replacement cycle fuel with a long interval of time, the waste management related to some fuels candidates its use and resistance to nuclear proliferation..
\end{abstract}

Keywords: comparison study, gas cooled fast reactor, long life operation, reactor safety systems, nuclear waste management.

\section{PENDAHULUAN}

Kebutuhan energi dunia yang terus meningkat seiring dengan meningkatnya populasi masyarakat dunia sementara cadangan energi tak terbarukan justru terus berkurang. Kebutuhan energi yang tinggi ini selain merupakan dampak dari bertambahnya populasi penduduk dunia, namun yang lebih besar pengaruhnya adalah peningkatan dan perkembangan teknologi yang sangat pesat akhir-akhir ini menyedot penggunaan energi yang sebanding dengan laju perkembangan-nya.

Energi nuklir muncul sebagai energi alternatif untuk menjawab kebutuhan energi masyarakat dunia tersebut. Saat ini telah banyak pembangkit-pembangkit listrik tenaga nuklir tersebar di seluruh dunia. Pembangkit listrik tenaga nuklir pada prinsipnya adalah pemanfaatan energi nuklir dari reaksi fisi terkendali yang kemudian dikonversikan menjadi bentuk-bentuk energi bagi kebutuhan energi dunia, terutama energi listrik. Pembangkit listrik tenaga nuklir yang sekarang sedang beroperasi merupakan generasi III yang bersiap-siap untuk memasuki masa henti operasi dan akan digantikan dengan reaktor generasi IV yang digadang-gadang dapat memberikan pasokan energi lebih besar, tingkat keamanan yang lebih tinggi, operasional yang lebih efisien serta penanganan limbah yang lebih aman dan terencana dengan baik.

Pasokan listrik yang dapat mengimbangi kebutuhan masyarakat merupakan salah satu permasalahan yang sedang dirasakan oleh Indonesia terutama sekali karena Indonesia masih 
mengandalkan sumber listriknya dari sumber-sumber energi tak terbarukan dan hanya fraksi kecil sumber energinya yang berasal dari sumber energi terbarukan seperti tenaga air, angin, panas bumi, sinar dan panas matahari dan lain sebagainya. Pembangkit listrik tenaga nuklir merupakan solusi yang harus segera diwujudkan oleh pemerintah Indonesia untuk menjawab tingginya kebutuhan pasokan listrik di Indonesia. Reaktor generasi IV dapat menjadi acuan bagi Indonesia dalam mewujudkan solusi tersebut.

Reaktor generasi IV merupakan sumber energi nuklir dengan rapat energi yang tinggi, konversi ke energi listrik yang lebih baik dan ramah lingkungan karena tidak menghasilkan gas penyebab efek rumah kaca. Selain itu, reaktor generasi IV juga menawarkan efisiensi yang lebih tinggi, penggunaan Uranium alam sebagai bahan bakar, sistem keselamatan pasif dan harga produksi yang lebih rendah (M. Ilham, 2017).

Gas-cooled Fast Reactor disingkat GFR merupakan salah satu kandidat dari reaktor generasi IV yang direncanakan akan beroperasi pada tahun 2030 yang memiliki spektrum neutron cepat dan dapat memanfaatkan Uranium alam sebagai bahan bakarnya. Tipe GFR yang akan dibahas dalam paper ini adalah GFR dengan daya tidak terlalu besar (small energy density) tetapi memiliki masa operasi yang cukup panjang, mencapai 100 tahun dengan masa refueling bahan bakar setiap 10 tahun (F. Monado, 2013).

\section{KAJIAN LITERATUR}

\section{a. Reaktor Generasi IV}

Program reaktor generasi IV ini dimulai tahun 1999 yang lebih menitikberatkan pada (1) Keberlanjutan (Sustainability) (2) Ekonomi (Economy) (3) Keselamatan raktor (Safety) dan (4) Keamanan dari tindakan pembiakan ilegal (Proliferation resistance). Pada tahun 2002 dibentuk Generation IV International Forum (GIF) yang terdiri dari 10 negara anggota. Pada forum ini kemudian ditetapkan 6 kandidat reaktor nuklir generasi berikutnya yaitu [Bodansky, 2004 : 471] :

a. Gas-Cooled Fast Reactor system (GFR)

b. Lead-Cooled Fast Reactor system (LFR)

c. Molten Salt Reactor system (MSR)

d. Sodium-Cooled Fast Reactor system (SFR)

e. Supercritical-Water-Cooled Reactor system (SCWR)

f. Very-High-Temperature Reactor system (VHTR)

Gambar 1 berikut memperlihatkan desain awal dari reaktor generasi IV yang menjadi fokus pengembangan pada perioda berikutnya. 


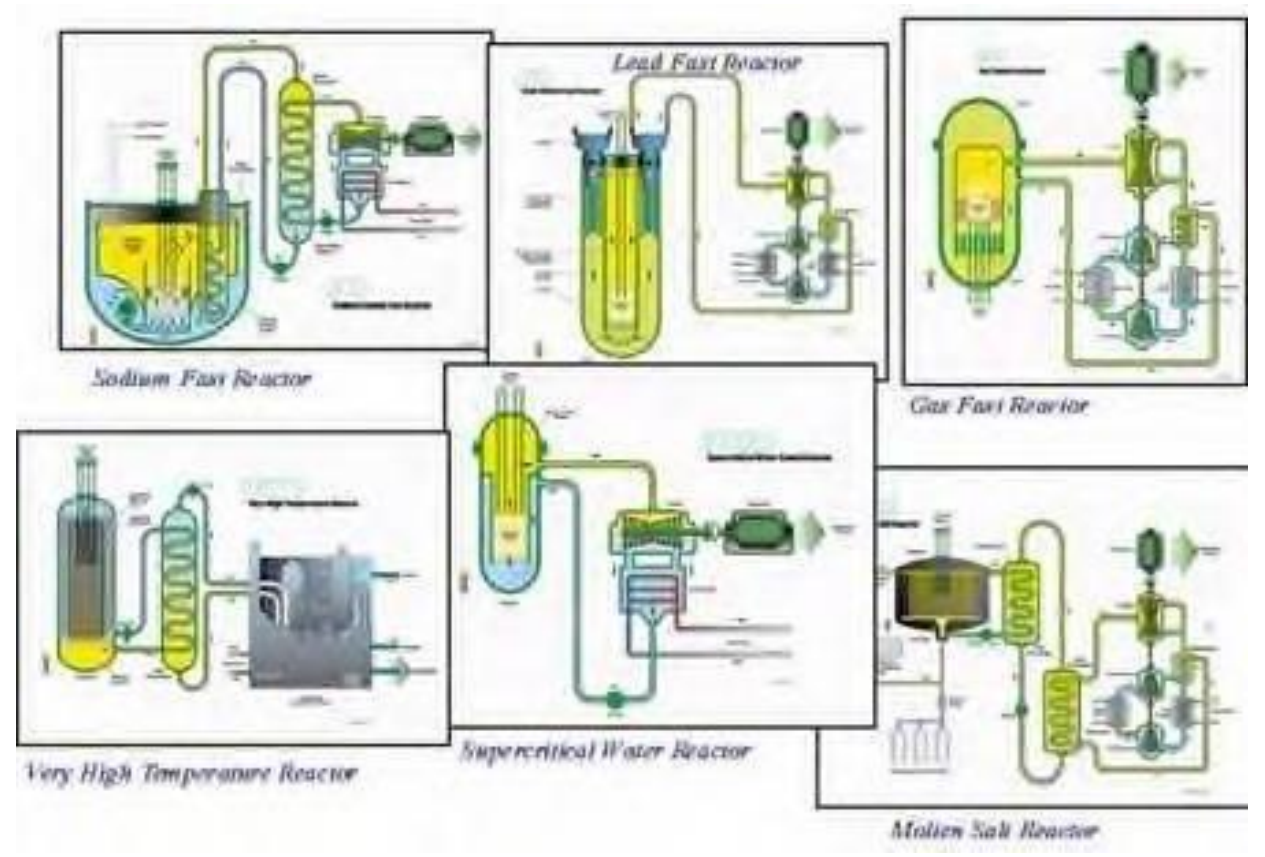

Gambar 1. Reaktor Generasi IV

Tabel 5. Nuclear Reactor System Generasi IV yang dikandidatkan oleh GIF

\begin{tabular}{|c|c|c|c|c|c|c|}
\hline Reactor Characteristic & VHTR & SCWR & GFR & SFR & LFR & MSR \\
\hline $\begin{array}{l}\text { Neutron spectrum } \\
\text { Coolant }\end{array}$ & $\begin{array}{l}\text { Thermal } \\
\text { Helium }\end{array}$ & $\begin{array}{l}\text { Either } \\
\text { Water }\end{array}$ & $\begin{array}{l}\text { Fast } \\
\text { Helium }\end{array}$ & $\begin{array}{l}\text { Fast } \\
\text { Sodium }\end{array}$ & $\begin{array}{l}\text { Fast } \\
\mathrm{Pb} \text { or } \\
\mathrm{PbBi}\end{array}$ & Thermal \\
\hline oderator & Graphite & Water $^{a}$ & None & None & None & Graphi \\
\hline & & & Yes & Yes & & Online \\
\hline ic size & NA & 3860 & $\mathrm{NA}$ & & 3600 & \\
\hline iic size & NA & 1700 & $\mathrm{NA}$ & $\approx 1500$ & 1200 & 1000 \\
\hline or Modular & 600 & $\mathrm{NA}$ & 600 & & $120-400$ & $\mathrm{NA}$ \\
\hline $\begin{array}{l}\text { Mid-size or Modular } \\
\text { (MWe) }\end{array}$ & & $\mathrm{NA}$ & 288 & $150-500$ & $50-150$ & $\mathrm{NA}$ \\
\hline gar & & 45 & & $50-200$ & & \\
\hline & & & & & 550 & \\
\hline Elec & & & & & & \\
\hline & & & & & At $800^{\circ} \mathrm{C}$ & At \\
\hline Year deployable & 2020 & 2025 & 2025 & 2015 & 2025 & 2025 \\
\hline
\end{tabular}

Tabel 1 di atas memperlihatkan deskripsi singkat keenam reaktor generasi IV. Berikut akan dibahas lebih lanjut tentang Gas-ccoled Fast Reactor (GFR).

\section{b. Gas-Cooled Fast Reactor (GFR)}

Gas-cooled Fast Reactor atau GFR adalah reaktor dengan temperatur operasi tinggi dengan pendingin menggunakan gas Helium dan dengan siklus bahan bakar tertutup. GFR GFR menggabungkan keunggulan reaktor dengan neutron cepat dan suhu operasi yang tinggi. Spektrum neutron cepat memberikan keuntungan tersendiri bagi reaktor ini karena dapat menggunakan Uranium alam sebagai bahan bakar serta dapat meminimalisir limbah nuklir karena pembakaran aktinida dan pendauran bahan bakar. Sedangkan suhu operasi yang tinggi dapat menghasilkan efisiensi tinggi pada siklus panas dan panas yang dihasilkan juga dapat digunakan untuk industri misalnya produksi gas hidrogen melalui reaksi pemisahan molekul air $\left(\mathrm{H}_{2} \mathrm{O}\right)$ menjadi Oksigen $\left(\mathrm{O}_{2}\right)$ dan Hidrogen $\left(\mathrm{H}_{2}\right)$. 
Gambar (2.a) memperlihatkan desain GFR. Pada gambar terlihat bentuk teras reaktor, pendingin, sistem pendingin, turbin dan generator dari GFR dan gambar (2.b) memperlihatkan heat exchanger dari reaktor.

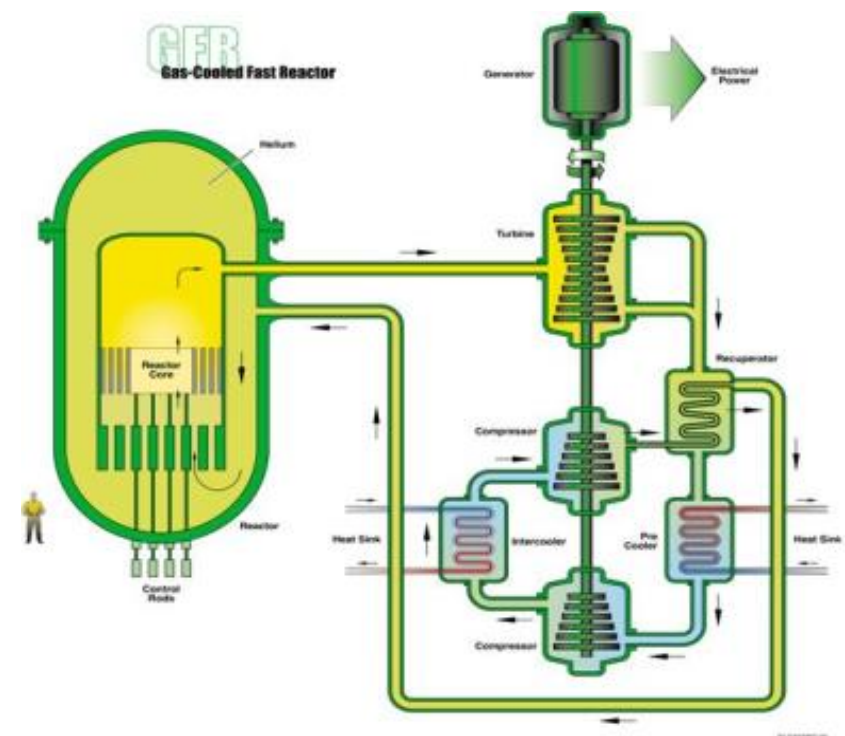

Gambar (2a). Desain GFR meliputi teras reaktor, sistem pendingin, turbin dan generator
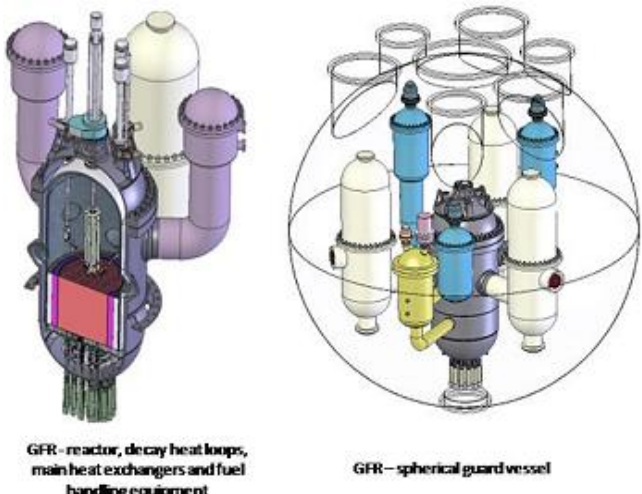

Gambar (2b). Heat Exchanger dari GFR

Beberapa kelebihan dari GFR antara lain :

a. Efisiensi lebih tinggi

b. Berjenis reaktor dengan neutron spektrum cepat sehingga dapat digunakan untuk pemanfaatan bahan bakar alami.

c. Membantu produksi Hidrogen yang dapat dimanfaatkan pada rancangan bahan bakar kendaraan / industri beberapa tahun ke depan.

d. Minimalisir limbah yang dihasilkan karena tingkat pembakarannya yang tinggi.

Berikut akan dibahas tentang GFR berdaya rendah dan berumur panjang (small long life Gasccoled Fast Reactor).

c. small long life Gas-cooled Fast Reactor 
Defenisi GFR berdaya rendah dan berumur panjang atau small long life Gas-cooled Fast Reactor ini yang dimaksudkan adalah GFR dengan daya relatif kecil, namun dirancang dapat beroperasi lama tanpa terlalu sering mengalami pertukaran bahan bakar (refueling). Tabel berikut memperlihatkan salah satu contoh spesifikasi dari reaktor ini :

Tabel 2.

Contoh Spesifikasi Small Long-Life Gas-cooled Fast Reactor (F. Monado, 2013)

\begin{tabular}{ll}
\hline Parameter & Value/Description \\
\hline Power (MWt) & 300 \\
Number of equal volume region & 10 \\
Fuel Material & U-10wt $\% \mathrm{Zr}$ \\
Cladding Material & Stainless Steel \\
Coolant Material & Helium \\
Fuel Volume fraction & $60 \%$ \\
Cladding Volume fraction & $10 \%$ \\
Coolant Volume fraction & $30 \%$ \\
Active core diameter & $220 \mathrm{~cm}$ \\
Active core height & $280 \mathrm{~cm}$ \\
Reflector radial width & $50 \mathrm{~cm}$ \\
Reflector axial width & $50 \mathrm{~cm}$ \\
Pin pitch & $1.4 \mathrm{~cm}$ \\
Sub cycle length & 10 years \\
Reactor life & 100 years \\
\hline
\end{tabular}

\section{METODE PENELITIAN}

Paper ini merupakan studi perbandingan (comparative study) yang memberikan deskripsi terkait dengan perkembangan pada perancangan dan persiapan penggantian reaktor generasi III yang sekarang sedang beroperasi dan beberapa sudah mencapai masa shut-down, dengan reaktor generasi IV yang memiliki beberapa kandidat, salah satunya adalah Gas-cooled Fast Reactor (GFR), oleh karena itu penelitian yang dilakukan tergolong kepada penelitian deskriptif. Teknik yang digunakan adalah studi kepustakaan dari sumber-sumber literatur meliputi buku dan jurnal.

\section{HASIL DAN PEMBAHASAN}

Fokus penulisan paper ini adalah melakukan studi perbandingan yang dimaksudkan sebagai studi awal / analisis awal dalam rangka pengembangan analis pada reaktor cepat berpendingin gas terutama pada safety analysis (penelitian berikutnya).

d. Efisiensi

F. Monado dkk, $(2013,2014)$ merancang reaktor berdaya kecil dengan masa aktif mencapai 100 tahun namun persiklusnya setiap 10 tahun tanpa penggantian bahan bakar (Refueling) namun dengan perputaran bahan bakar (fuel shuffling). Simulasi yang dilakukan dengan SRAC dan memperlihatkan kestabilan dari reaktor dan dapat beroperasi persiklus selama 10 tanpa refueling serta dapat memanfaatkan Uranium alam sebagai bahan bakarnya.

M.Ariani (2011) dkk merancang reaktor berdaya kecil dengan sistem pola siklus bahan bakar yang sama dengan F. Monado, namun terfokus pada pengecekan bahan bakar yang tepat. M. Ariani mendapatkan penambahan unsur $\mathrm{Zr}$ pada bahan bakar dapat meningkatkan kestabilan dan ketahanan bahan bakar. 


\section{e. Safety system}

Sistem keselamatan yang ditawarkan pada GFR adalah tipe sistem pasif. Pendingin sepenuhnya dapat bergerak sepanjang teras karena konveksi alami. Sejak kecelakaan nuklir Fukushima (R. Anshari, 2012), fokus penerapan reaktor dengan passive safety system semakin menguat dan reaktor generasi ke IV yang menerapkan passive system seperti GFR dapat dijadikan kandidat yang memiliki potensi besar.

\section{f. Dukungan pada perkembangan Ekonomi}

Yang menjadi pertimbangan pada dukungan GFR terhadap perkembangan ekonomi adalah pasokan energi yang memadai yaitu dengan menawarkan / mengupayakan GFR yang dapat beroperasi dengan daya keluaran besar namun dengan efisiensi yang lebih baik. Selain itu karena GFR beroperasi pada temperatur tinggi, keadaan ini dapat dimanfaatkan untuk sumber energi dalam produksi Hidrogen.

Hidrogen sendiri merupakan salah satu bahan bakar alternatif dikarenakan hasil pembakarannya tidak menghasilkan gas rumah kaca (green house effect). Pada industri, penggunaan Hidrogen sebagai sumber bahan bakar mendapat perhatian yang cukup besar. Permaslahan sekarang salah satunya adalah produksi hidrogen yang masih mahal selain faktor proteksinya terhadap kecelakaan (protection). GFR menawarkan produksi gas Hidrogen yang relatif hemat karena merupakan hasil sampingan/tambahan dari reaktor yang beroperasi pada suhu tinggi.

\section{KESIMPULAN}

Studi perbandingan ini bermaksud sebagai studi awal untuk melihat seberapa besar potensi GFR sebagai kandidat reaktor generasi ke IV. Perbandingan dilakukan terhadap beberapa hasil penelitian yang telah dilakukan oleh beberapa peneliti memperlihatkan GFR memiliki potensi yang cukup besar untuk dapat beroperasi beberapa tahun ke depan. Diantara kekuatan GFR adalah :

a. Menawarkan efisiensi yang lebih baik

b. Menerapkan sistem keselamatan pasif

c. Menawarkan produksi gas Hidrogen sebagai penunjang ekonomi, baik dari sektor industri maupun dari sektor transportasi.

Masih diperlukan analisis mendalam terhadap potensi ini untuk hasil yang lebih baik ke depannya.

\section{REFERENSI}

F. Carre, P. Yvon, P. Anzieu, N. Chauvin dan J. Malo; Update of The French R\&D Strategy on Gas Cooled Reactor; Nuclear Engineering and Design Vol. 240 p. 2401-2408; Elsevier (2010) 
F. Monado, Z. Su'ud, A. Waris, K. Basar, M. Ariani dan H. Sekimoto; Power Flattening on Modified CANDLE Small Long Life Gas-cooled Fast Reactor; Advance Nuclear Research and Energy Development, AIP Conf. Proc. Vol 1615 p.47-50 (2014)

F. Monado, M. Ariani, Z. Su'ud, A. Waris, K. Basar, F. Azis, S. Permana dan H. Sekimoto; Conceptual Design Study on Very Small Long-Life Gas Cooled Fast Reactor using Metallic Natural Uranium-Zr as Fuel Cycle Input; Advance Nuclear Research and Energy Development, AIP Conf. Proc. Vol 1584 p.105-108 (2014)

F. Monado, Z. Su'ud, A. Waris, K. Basar, M. Ariani dan H. Sekimoto; Aplication of Modified CANDLE Burn-Up to Very Small Long Life Gas-cooled Fast Reactor; Advance Materials Research Vol. 772 p. 501-506 (2013)

G. Locatelli, M. Mancini dan N. Todeschini; GEN IV Reactors : Where We Are, Where We Should Go; Proceeding of ICAPP Paper 12229 p.1104-1113 (2012)

M. Ariani, Z. Su'ud, A. Waris, Khairurrijal, F. Monado dan H. Sekimoto; The Feasibility Study of Small Long Life Gas Cooled Fast Reactor with Mixed Natural Uranium/Thorium as Fuel Cycle Input; Advance Nuclear Research and Energy Development, AIP Conf. Proc. Vol 1448 p.59-64 (2011)

M. Ilham dan Z. Su'ud ; Design Study of Modular Nuclear Power Plant with Small Long Life Gas Cooled Fast Reactors Utilizing MOX Fuel; IOP Conf. Series, Journal of Physics Conf. Series 799 p.1 (2017)

P. Dumaz, P. Allegre, C. Bassi, T. Cadiou, A. Conti, J.C. Garnier, J.Y. Malo dan A. Tosello; Gas-cooled Fast Reactors - Status of CEA Preliminary Design Studies; Nuclear Engineering and Design Vol. 237 p. 1618-1627; Elsevier (2007)

R. Stainsby, K. Peers, C. Mitchell, C. Poette, K. Mikityuk dan J.Somers; Gas Cooled Fast Reactor Research in Europe; Nuclear Engineering and Design Vol. 241 p. 3481-3489; Elsevier (2011)

R. Anshari; Preliminary Analysis of Loss-of-Coolant Accident in Fukushima Nuclear Accident; The American Institute of Physics (AIP) Conference Proceedings Vol. 1448 p. $315-327 ; 2012$.

Z. Su'ud; Unprotected Loss of Flow Accident in Small Long Life Gas Cooled Fast Reactor; Applied Mechanics and Materials Vol. 751 p.263-267 (2015) 